\title{
Forecasting the Future of Renewables
}

\author{
Seppo Valkealahti \\ Tampere University of Technology \\ Finland
}

\section{Introduction}

The global electric power consumption has increased for decades and the growth seems to continue in the foreseen future. At the same time the known conventional fossil energy resources will be decreasing and, evidently, we will be short of them. On top of that we are facing serious problems of climate change due to $\mathrm{CO}_{2}$ emission. These kind of giant problems ahead of us have finally raised a genuine interest on the utilization of alternative energy sources. First we will face the shortage of oil and gas, which can be substituted for some time with energy sources like coal and beat, if environment and climatic issues are ignored. However, climatic change is a major driver in energy sector at the moment, and only renewable energy sources provide a sustainable outlook.

Renewable energy sources cover only a fraction of the present energy consumption, because most of them are not competitive on the market. Only hydropower is clearly competitive. In special cases also other renewable energy sources can be competitive, for example, biomass as a source of combined heat and power. Major technology development is still needed for most of the renewable energy sources to achieve market penetration. Both on public finance and private business decision point of view it is essential to know, when these evolving electric power production technologies are competitive on the market and what is their foreseen market volume, i.e., electric energy production potential. Market penetration depends on the development of the evolving energy production technology in question and on the forthcoming cost of electric energy production using conventional primary energy sources.

To forecast the market diffusion of new evolving electric energy production technologies, the dependence of the market diffusion on technology and energy market variables need to be analysed. Market diffusion can be analysed with various qualitative or quantitative methods, which all involve a considerable amount of uncertainty. If a reasonable amount of historical data of the evolution of the technology is available, quantitative methods can be applied to forecast the market penetration. Due to numerous uncertainties related to the input parameters it has turned out that a simple and straightforward method is usually as good as a more sophisticated method. At the end on long term market mechanics will rule out the development and the analyses can be based on the production cost of electrical energy. Production cost depends basically on environmental variables, such as the availability of the energy source used, and on variables related to the production technology in question, like the investment cost.

Production costs of electrical energy for most renewable energy sources are mainly due to investment costs and to some extend on production and maintenance costs, but the energy 
source is free of costs. In these cases production costs can be estimated based on technology learning, i.e., concepts like learning factor and progress ratio. In addition to investment, production and maintenance costs power production costs for conventional non-renewable energy sources are based on fuel prices. Conventional technologies are already quite mature with slow learning rate. Therefore, changes in power production costs are mainly due to changes in fuel prices.

In this chapter it will be demonstrated how technology development and market penetration of evolving energy production technologies can be forecasted by quantitative methods. In particular, we look on electric power production, because its role in the energy sector increases both absolutely and relatively. We have analyzed the relevant variables for power production costs, their dependencies on each other and their future development on long term. These issues have been combined with feasible technology evolution and market diffusion models (Armstrong, 2001; Junginger, 2005; Martino, 1993; Meredith \& Mantel, 1995; Rogers, 2003). We will show that a plausible model can be developed to forecast, when an evolving new power production technology becomes competitive on the market. We also analyse the market penetration of photovoltaic power production with this model. This simple model can be applied quite easily also to other evolving power production technologies to obtain useful forecasts.

\section{Production cost of electrical energy}

World net electricity generation has globally increased until 2010 with an average annual rate of $3.0 \%$ outpacing the growth of total energy consumption by $1.3 \%$. World net electricity generation will increase by an average of $2.3 \%$ per year until 2035 according to the IEO2010 Reference Case continuing to outpace the growth in total energy usage throughout the projection period. This will end up to an increase by $87 \%$ to $35000 \mathrm{TWh}$ until 2035. High fossil fuel prices recorded between 2003 and 2008, combined with concerns about the environmental consequences of greenhouse gas emissions, have renewed interest in the development of alternative energy sources with respect to fossil fuels-specifically, nuclear power and renewable energy sources. In the IEO2010 Reference Case, long-term prospects continue to improve for generation from both nuclear and renewable energy sources. Coal is foreseen to cover most of the growth of electricity generation with $7000 \mathrm{TWh}$ and renewable energy sources are the second sources covering 4500 TWh of the growth. Renewable energy sources have the largest growth rate in electricity generation in the IEO2010 Reference Case with an average annual growth of $3.0 \%$. This will end up to an increase by almost $130 \%$ until 2035. Accordingly, the renewable share of world electricity generation would grow from $18 \%$ in 2007 to $23 \%$ in 2035 . Majority of this growth will be due to the increase in wind and solar power production. (EIA, 2010b)

The era of change from the utilisation of fossil energy to renewable energy seems to be inevitable when we run out of fossil fuel resources. The transition will be ruled out by "market forces" on demand and supply basis. It is quite realistic to anticipate that the prices of conventional energy resources will increase while their stock decreases. This means that alternative energy production technologies will become more competitive. At the same time the cost of new evolving energy technologies can be estimated to decrease following typical technology development trends. In the following basic outlines are given how to forecast this technology transition. First the basic outlines to evaluate production costs of electricity 
generation from conventional energy sources are presented and then for evolving electricity production technologies from renewable energy sources.

\subsection{Conventional power production technologies}

Oil, natural gas, coal and beat covered $81.2 \%$ of the global primary energy consumption in 2008 and $87.0 \%$ of the total primary energy usage was covered by non-renewable fuels. $5.5 \%$ of the total electrical energy was produced by oil, $21.3 \%$ by natural gas, $40.0 \%$ by coal and beat and $13.5 \%$ by nuclear energy. Hydropower covered $15.9 \%$ leaving only a share of $2.8 \%$ for other renewable energy sources. (IEA, 2010a) The average global growth rate of electric power usage has been estimated to be larger than the growth rate of total energy usage in the future and new renewable energy sources will have the highest relative growth. However, the biggest total grow in power production will be in the use of coal. (EIA, 2010b)

Conventional power production technologies have been utilized for several decades and they are quite mature. The main technologies have also very high volumes in power production, which means that their relative capacity does not increase rabidly. Therefore, the technological development can be expected to be quite modest in the future and no major changes in investment, production and maintenance costs are expected. For simplicity, these variables can be supposed to stay constant as a function of time for conventional power production technologies.

Production cost of electrical energy $C$ with conventional technologies can be calculate by

$$
C=\frac{a C_{I}+C_{P}}{t_{c}}+\frac{C_{F}}{\eta}
$$

where $a$ is the annuity factor of the investment, $C_{I}$ the investment cost, $t_{c}$ the annual capacity factor, $C_{P}$ the annual production and maintenance cost, $C_{F}$ the fuel price and $\eta$ the energy efficiency of the power station. Emission cost of $\mathrm{CO}_{2}$ could be included in the fuel price, but has not been included in this analysis, because emission cost is more a political than a technological parameter.

Globally the main energy sources in power production are coal, natural gas, hydropower, nuclear energy and oil. Hydropower and nuclear power are the low cost basic sources of electrical energy. In most parts of the world the marginal price of electrical energy follows the cost of natural gas or coal thermal electric power production, and changes in the production costs are primarily due to changes in fuel prices. Oil has a quite global price and, therefore, it would be an ideal reference price for analysing global energy cost issues. However, oil is not a basic source of electrical energy in all parts of the world due to its limited resources and high price. Therefore, it is not suitable for defining global marginal price of electrical energy.

Natural gas has quite global price, which follows the oil price closely. Coal price is more local, but it also follows the oil price to some extent. As an example of this, the oil, natural gas and coal prices in the European Union are presented in Figure 1 from 1985 to 2005. Market prices of natural gas and coal follow the oil price closely having correlation coefficients of 0.88 and 0.76 , respectively. Furthermore, there seems to be a direct pricing mechanism between oil and gas, because the gas price and the oil price shifted one year ahead have a correlation of 0.94 . Due to these strong correlations oil, natural gas and coal prices can be expected to have roughly the same increase rate in the future. 


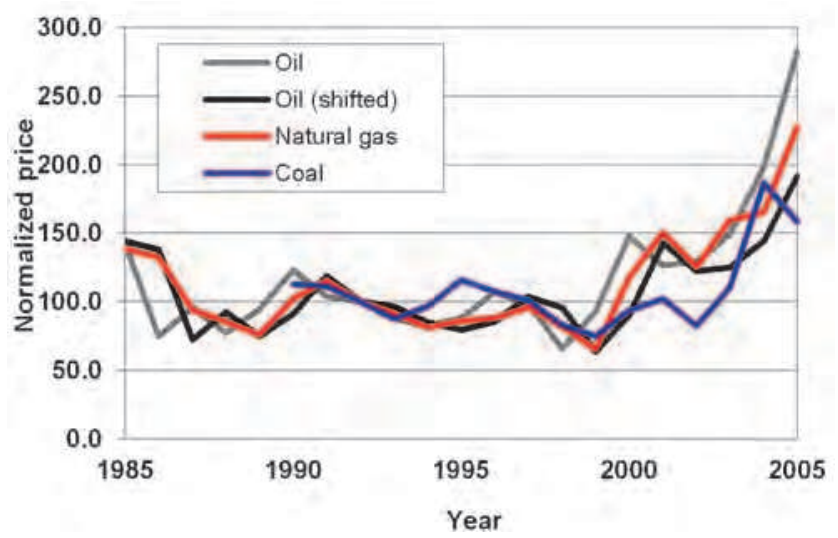

Fig. 1. Oil, natural gas and coal prices in EU in the period from 1985 to 2005 normalized to 100 in 1992. The black line is the oil price of the previous year. (British Petroleum, 2006; Valkealahti \& Nevaranta, 2007)

Coal has the largest resources of conventional energy in the world and its resources are distributed quite evenly around the world. It also has the lowest market price. For example, in 2008 in electric power sector the price of natural gas was over 4 times higher than the price of coal in term of energy content and oil was over 7 times more expensive (EIA, 2010a). Therefore, it is plausible to assume that in most parts of the world the marginal price of electrical energy is determined by the coal price. This situation can be anticipated to stay also in the future, because the fossil fuel prices are strongly connected to each other and no major relative changes are expected. For these reasons, coal thermal electric power production has been selected to be the reference fossil source of electrical energy in analysing market diffusion of evolving power production technologies based on renewable energy sources.

All variable values used in this work correspond to the state of the art modern technology. For all variables we have defined a reference value, which is in many cases a mean value of a representative sample of technologies or a value from a most probable scenario given for the future. In 2008 the average investment costs of modern thermal coal power stations around the world have been analysed to be close to $1400 € / \mathrm{kW}$ (IEA, 2010b). Based on Valkealahti and Nevaranta (Valkealahti \& Nevaranta, 2007) investment costs for about $80 \%$ of the coal power stations can be estimated to be between 1250 and $1550 € / \mathrm{kW}$. These values have been used as the minimum and maximum values to describe the variation of the investment costs in the analyses later on (Table 1).

Annual production and maintenance costs for coal thermal electric power production are typically around $4 \%$ of the investment costs (IEA, 2010b). Annual production time of a thermal power plant varies considerably depending on a large number of variables. Typically electric loads in the network have seasonal and also shorter term variations causing breaks in production, regular maintenance is needed etc. If a power plant would operate the whole year with nominal power without breaks, the capacity factor $t_{c}$ would reach its maximum value of 8760 hours. However, a typical utilization rate of a thermal power plant corresponds to a capacity factor of the order of 6000 hours. A maximum capacity factor of 8000 hours is achievable with normal service breaks. In areas with high 
seasonal variations effective time for annual power production can be around 4000 hours, which can be used as a practical lower limit. Economic lifetime of a coal thermal electric power plant is typically around 30 years and efficiency of a modern power plant is around $40 \%$. The annuity factor has been calculated with a fixed annual interest of $5 \%$. These values have been used in this analysis as reference values and they are presented also in Table 1. Also the minimum and maximum limits for the technology related parameters have been introduced to study the sensitivity of technology diffusion on different parameters. Only annual interest rate has been fixed, because it is not directly related to technology development. (IEA, 2005; IEA, 10b)

\begin{tabular}{|c|c|c|c|}
\hline Variable & Minimum & Reference & Maximum \\
\hline $\begin{array}{c}\text { Investment cost }(€ / \mathrm{kW}) \\
\text { Annual production and maintenance cost } \\
(€ / \mathrm{kW})\end{array}$ & 50 & 60 & 1500 \\
\hline Economic lifetime $(\mathrm{y})$ & 25 & 30 & 70 \\
\hline Capacity factor $(\mathrm{h})$ & 4000 & 6000 & 8000 \\
\hline Efficiency & 0.35 & 0.40 & 0.45 \\
\hline Interest rate $(\%)$ & & 5 & \\
\hline Coal price $(€ / \mathrm{MWh})$ & & 8 & \\
\hline Annual coal cost growth rate by IEA (\%) & -0.8 & 1.9 & 3.3 \\
\hline Annual coal cost growth rate by EPIA (\%) & 0.4 & 2.0 & 3.6 \\
\hline
\end{tabular}

Table 1. Input variables to calculate production costs of coal thermal electrical energy. The reference values are considered to be the most probable values. Also estimated $10 \%$ and 90 $\%$ uncertainty ranges are given. (IEA, 2005; IEA, 10b; EPIA, 2010)

The known fossil energy resources of coal, oil, natural gas and $\mathrm{U}^{235}$ have been estimated to last about 220, 40, 60 and 70 years, respectively, with the present consumption and roughly the same amount of resources are estimated to be found more (British Petroleum, 2006; British Petroleum, 2004; EIA, 2002). Based on this information it has been estimated that somewhere between 2020 and 2050, the primary energy consumption of non-renewable energy sources will start to decrease. This transition will be preceded by a considerable increase of primary energy prices. Therefore, the long term primary energy price development of fossil fuels has to be taken into account in technology diffusion analyzes.

Coal prices have typically changed marginally mostly due to the large resources compared to other fossil fuels and to the current usage of coal. During the last decade coal price has increased considerably following the rapid growth of oil price, but during the last years it has returned close to the long term price level. To have a realistic starting point for analysing the future coal thermal electric power production costs, an average of the last 10 year has been used as a current coal price. By this way the most dramatic effects of short term price fluctuations were reduced.

In Table 1 there has been presented also scenarios for the future coal price by International Energy Agency and European Photovoltaic Industry Association until 2035 and 2030, respectively (IEA, 2010a; EPIA, 2010). Both scenarios actually predict fluctuating growth rates for the projection period from which we have calculated average growth rates to be used in our analysis. In both scenarios low and high coal costs estimates are given in addition to the most probable reference estimates for price development. The reference cost 
growth rates in the two scenarios are almost the same and also the high cost growth rates are close to each. Only the low cost estimates differ considerably from each other, IEA providing even a negative annual growth rate estimate of $-0.8 \%$. This does not seem to be feasible and, therefore, the coal cost growth rates predicted by EPIA have been used as our reference in the analysis.

\subsection{Evolving renewable power production technologies}

The cost of electrical energy produced by evolving renewable power production technologies can be calculated with equation (1) basically in the same way as for conventional technologies. The main difference is that the investment, production and maintenance costs of evolving technologies are still decreasing strongly due to technical, manufacturing, process etc. development. This kind of technology cost development can be described by a learning curve (Junginger, 2005), where a variable, like the investment cost $C_{I}$, is a function of the cumulative manufacturing volume $q$ of the technology

$$
C_{I}(t)=C_{I}\left(t_{0}\right)\left[\frac{q(t)}{q\left(t_{0}\right)}\right]^{-b},
$$

where $t$ is the time of interest, $t_{0}$ the reference point of time and $b$ the learning factor. Learning factor $b$ is typically defined by the relative price change called progress ratio $P R$, when cumulative production has doubled

$$
P R=2^{-b} .
$$

Technology development is commonly known to follow learning curves, where product cost or some other market related quantity decreases exponentially as a function of cumulative production. Also the development of solar photovoltaic electricity generation technology, which we use as an example of evolving renewable electric power production technologies to demonstrate the method of forecasting market penetration of new evolving renewable electric energy production technologies, follows the exponential learning curve development. Several studies have been done on the development of solar photovoltaic power technology providing progress rations for investment costs in the range from 0.75 to 0.82. For example, a progress ratio 0.75 has been obtained for the period from 1976 to 2002 (Poponi, 2003) and 0.77 for the period from 1981 to 2000 (Parente et al., 2002). A resent analysis for the period from 1980 until 2015 provides a progress ratio 0.80 (Beneking, 2007). Progress ratio tends to increase with increasing cumulative production volume meaning that the learning rate $L R=1-P R$ decreases. Simple explanation for this is that it is easier to improve a new technology than a mature technology. This seems to be the case also with solar photovoltaic technology to some extent.

We have used the progress ratio 0.80 for solar photovoltaic power technology in the analysis corresponding to a $20 \%$ decrease of the investment cost, when the cumulative manufacturing volume doubles. This is in line with historic development and resent estimates (Beneking, 2007). Investment cost is a major cost factor in generating electricity with solar photovoltaic power plants. Energy source for solar photovoltaic power is totally free, it is free of annual production costs and also maintenance costs are minimal. Therefore, solar photovoltaic electricity costs are predominantly based on the investment $\operatorname{cost} C_{I}$ and its 
future development can be estimated by using equations (2) and (3). In practice, electricity production cost by solar photovoltaic depends also on the capacity factor in addition to the investment cost. Capacity factor is a local quantity depending on the latitude, climatic conditions etc. For example, Central and North Europe have roughly the same capacity factors, but in South Europe, like in Spain, the capacity factor is much larger. In realistic areas on the Earth for solar photovoltaic electricity generation costs are between 220 and 440 $€ / M W h$ (EREC, 2008) due to different capacity factors. We have used these productions costs as low and high estimates for current costs and the median value of $330 € /$ MWh as the most probable value at our reference point of time (Table 2). Other cost variables for solar photovoltaic power production are considered to be time independent.

To be able to calculate the future investment or production cost of an evolving electricity generation technology based on technology learning rate we need to know the development of the manufacturing volume. International Energy Agency (IEA) and European Renewable Energy Council (EREC) have both estimated the future increase of installed capacity for different power production technologies, which use renewable energy resources (IEA, 2004; EREC, 2003). Most resent estimates for the cumulative growth of installed production capacity of solar photovoltaic power have been done by European Photovoltaic Industry Association (EPIA), EREC and IEA (EPIA, 2008; EREC, 2008; IEA, 2010). All these estimates have decreasing trends for the cumulative capacity growth rate starting from the current level of about 33 \% per year decreasing down to around $5 \%$ after 2040 as shown in Figure 2. Almost identical cumulative capacity, investment cost and production cost estimates for solar photovoltaic electricity generation were achieved by using these growth rate estimates, because they differ so little from each other. Therefore, we have used the estimated growth rate by EREC in our detailed analysis later on, which extends to 2050.

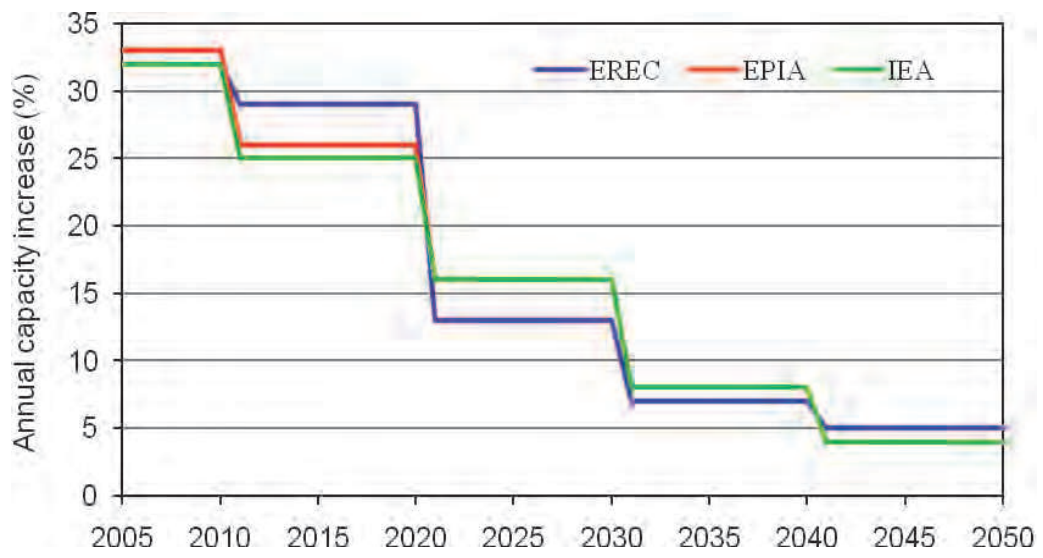

Fig. 2. Annual increase of the cumulative installed production capacity of solar photovoltaic electricity generation estimated by EPIA, EREC and IEA for the period from 2005 to 2050. The estimate by EPIA extends only to 2030. (EPIA, 2008; EREC, 2008; IEA, 2010)

To introduce range of variation for the estimated annual increase of the cumulative installed production capacity, it has been multiplied by a capacity growth factor (Table 2). A growth factor of 1.0 gives the original EREC estimate and factors 0.50 and 1.50 give low and high 
extremes for the growth. By this way it was possible to analyse the sensitivity of our forecasting model and the technology development on uncertainties in input variables. The same was done also with progress ration by introducing low and high limits of 0.75 and 0.85 , respectively.

\begin{tabular}{|c|c|c|c|}
\hline Variable & Minimum & Reference & Maximum \\
\hline Electricity production cost $(€ / \mathrm{kWh})$ & 220 & 330 & 440 \\
\hline Capacity growth factor & 0.5 & 1.0 & 1.5 \\
\hline Progress ratio & 0.75 & 0.80 & 0.85 \\
\hline
\end{tabular}

Table 2. Input variables to calculate production cost for solar photovoltaic electrical energy. The reference values are considered to be the most probable values. Also estimated $10 \%$ and $90 \%$ uncertainty ranges are given. (EREC, 2008; Poponi, 2003; Parente et al., 2002; Beneking, 2007)

\section{Market penetration of solar photovoltaic electricity generation}

Market penetration of solar photovoltaic electricity generation has been analysed with respect to thermal coal based power generation to demonstrate how diffusion of evolving renewable electricity generation technologies and their market penetration can be plausibly estimate by using a simple and straightforward method. Development and market penetration of evolving renewable power production technologies involve so many uncertainties and variables that it is, in practice, waste of time for doing very sophisticated analyses. It is actually more fruitful to figure out causes and effects of the most important factors for the development by a simple method.

There are several rational ways to define market penetration and none of those is the best without objection. Our choice for the reference is the production cost of coal thermal power, which in most parts of the world defines the marginal cost of electrical energy production. Coal is the cheapest source of fossil energy due to its largest recourses. Also coal price can be expected to incline least of all the fossil energy sources. Furthermore, solar photovoltaic electricity is available only when Sun is shining. For economical reasons it should be produced and used always when the energy source is available. Therefore, it can be considered as a basic source of energy in the same way as coal thermal electricity.

For each input variable of solar photovoltaic or coal thermal electricity generation a medium or most probable value has been used as a reference. These reference values have been used to calculate the reference forecast of market penetration, i.e., the point of time when solar photovoltaic achieves grid parity with coal thermal electricity generation. In Figure 3 the reference forecasts for the costs of solar photovoltaic and coal thermal electricity have been presented for the period from 2010 to 2050 . The point of grid parity in the reference case takes place in 2036 and has been marked by "Ref" in Figure 3.

In addition to the reference values feasible minimum and maximum values have been introduced for each variable to be able to evaluate the sensitivity of the market penetration on different factors. When statistical data on a certain variable was available $10 \%$ and $90 \%$ uncertainty values have been used as minimum and maximum values. For many variables value range or extreme forecasts from reliable reference sources have been used as minimum and maximum values. Sensitivity of the market penetration on different input 
variables has been tested by changing the value of one variable at a time while other variables have their reference values.

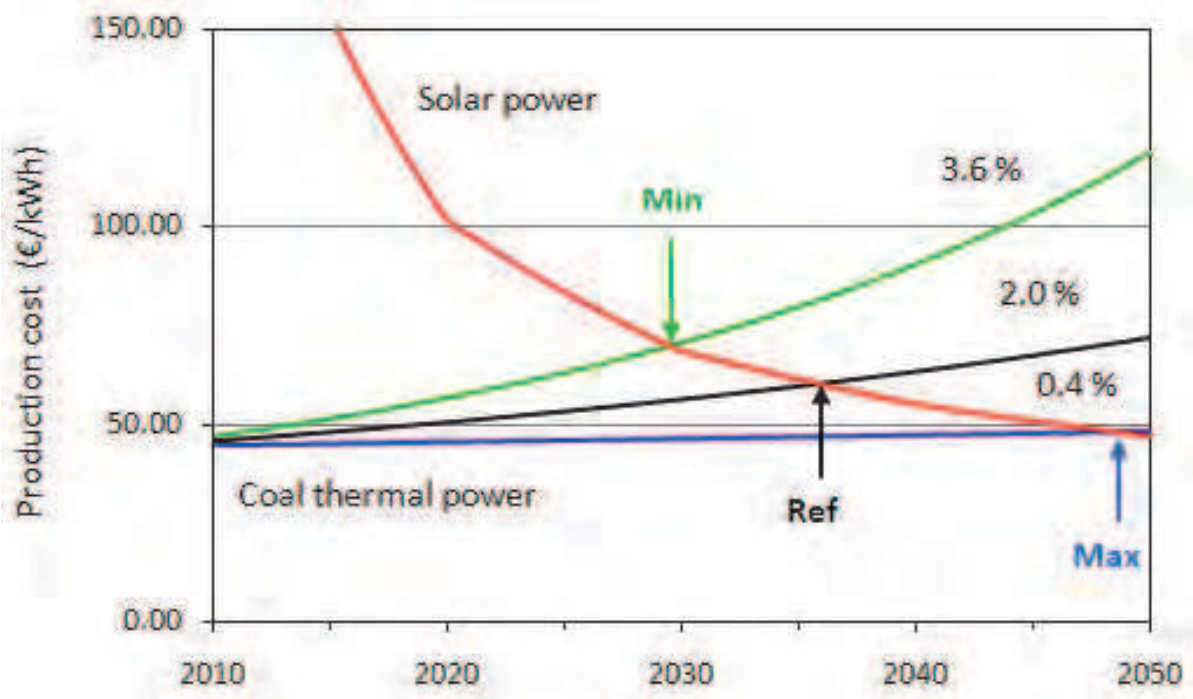

Fig. 3. Estimated electrical energy production costs for the period from 2010 to 2050 by solar photovoltaic and coal thermal power stations. Electricity production costs using coal are shown with estimated minimum, reference and maximum annual coal price growth rates of $0.4,2.0$ and $3.6 \%$, respectively. (EPIA, 2010)

One of the main uncertainties to forecast market penetration of solar photovoltaic technology is related to the uncertainty of the forthcoming cost of coal. To foresee the price of coal in the future is very difficult. Therefore, the use of a conservative forecast is justified, like the one provided by Europian Photovoltaic Industry Association with an annual coal price growth rate of $2.0 \%$ as a reference scenario and 0.4 and $3.6 \%$ as low and high growth rate scenarios, respective (EPIA, 2010). Calculated electricity generation costs with growth rates of 0.4 and $3.6 \%$ are shown in Figure 3. Grid parities are achieved in 2048 and 2030, accordingly. Market penetration of solar photovoltaic takes place only 6 year earlier, if the coal price growth rate increases from 2.0 to $3.6 \%$, but will be delayed by 12 years, if the growth rate is decreased to $0.4 \%$. This demonstrates that coal price, and more commonly fossil fuel prices, has a major effect on the market penetration of solar photovoltaic technology.

Capacity factor of coal thermal electricity generation has also a major effect on solar photovoltaic electricity market penetration. The coal thermal electricity generation costs until 2050 for capacity factors 4000, 6000 and 8000 hours are shown in Figure 4. The cost curve shifts to higher costs with decreasing capacity factor as expected. With the capacity factor of $4000 \mathrm{~h}$ the grid parity will be achieved already in 2030, but with a capacity factor of $8000 \mathrm{~h}$ only in 2039 . This demonstrates that market penetration of solar PV is strongly a local issue. If coal thermal power is used to generate electricity for basic loads with a capacity factor of $8000 \mathrm{~h}$, market penetration will take place 9 years later than in the case of seasonal usage of coal thermal power with a capacity factor of $4000 \mathrm{~h}$. 


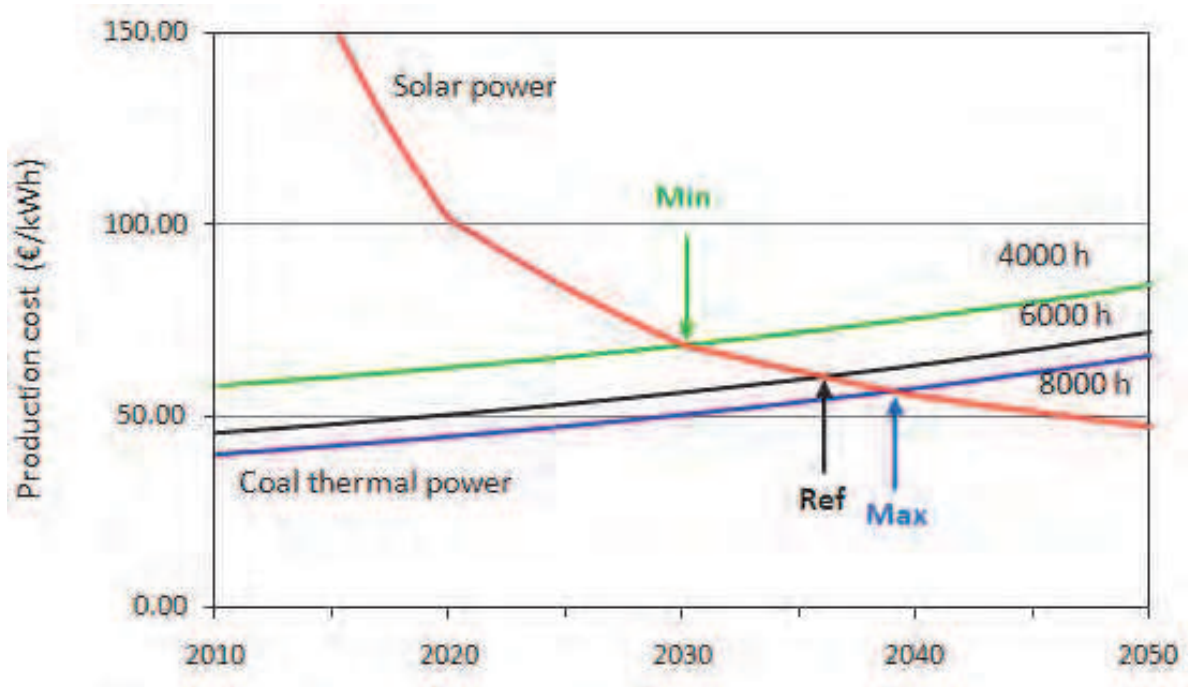

Fig. 4. Estimated electrical energy production costs for the period from 2010 to 2050 by solar photovoltaic and coal thermal power stations. Electricity production costs using coal are shown with estimated minimum, reference and maximum annual coal thermal power capacity factors of 4000, 6000 and 8000 hours, respectively.

As already discussed in section 2.2, solar photovoltaic power production costs are between 220 and $440 € / \mathrm{MWh}$ in realistic areas on the Earth for photovoltaic power production (EREC, 2008). Electricity production costs by solar photovoltaic power plants for the period from 2010 to 2050 are shown for current production costs of 220, 330 and $440 € / \mathrm{MWh}$ in Figure 5. Solar photovoltaic electricity cost curve shifts upwards with increasing initial production cost so that the grid parity moves from 2026 for the lowest cost of $220 € / \mathrm{MWh}$ up to 2045 for the highest cost of $440 € / M W h$. Solar photovoltaic electricity production costs have been reported to be $440 € / \mathrm{MWh}$ in Berlin, $390 € / \mathrm{MWh}$ in Paris, $330 € / \mathrm{MWh}$ in Washington, $300 € / \mathrm{MWh}$ in Hong Kong, $280 € /$ MWh in Sydney and Madrid, $250 € / \mathrm{MWh}$ in Bangkok and $220 € /$ MWh in Los Angeles and Dubai in 2007 (EPIA, 2008). This means that in places like Los Angeles and Dubai solar photovoltaic technology would penetrate fully to the market already in 2026, but in Central and North Europe the market penetration would take place only in 2045.

The uncertainties on market penetration of solar photovoltaic electricity due to uncertainties in input variables of the model have been presented in Figure 6 . The reference market penetration in the year 2036 has been calculated using the reference values of variables for solar photovoltaic power and coal thermal power (Tables 1 and 2). Minimum and maximum variable values have been used to evaluate the sensitivity of the market penetration on the uncertainty of each input variable. Minimum and maximum market penetration times have been calculated by changing the value of one input variable at a time while the other input variables have their reference values.

The biggest uncertainty seems to come from the production capacity growth (capacity growth factor) of solar PV power. If the cumulative solar photovoltaic electricity production capacity growth rate is only half from the forecasted growth rate (Figure 2), the market 


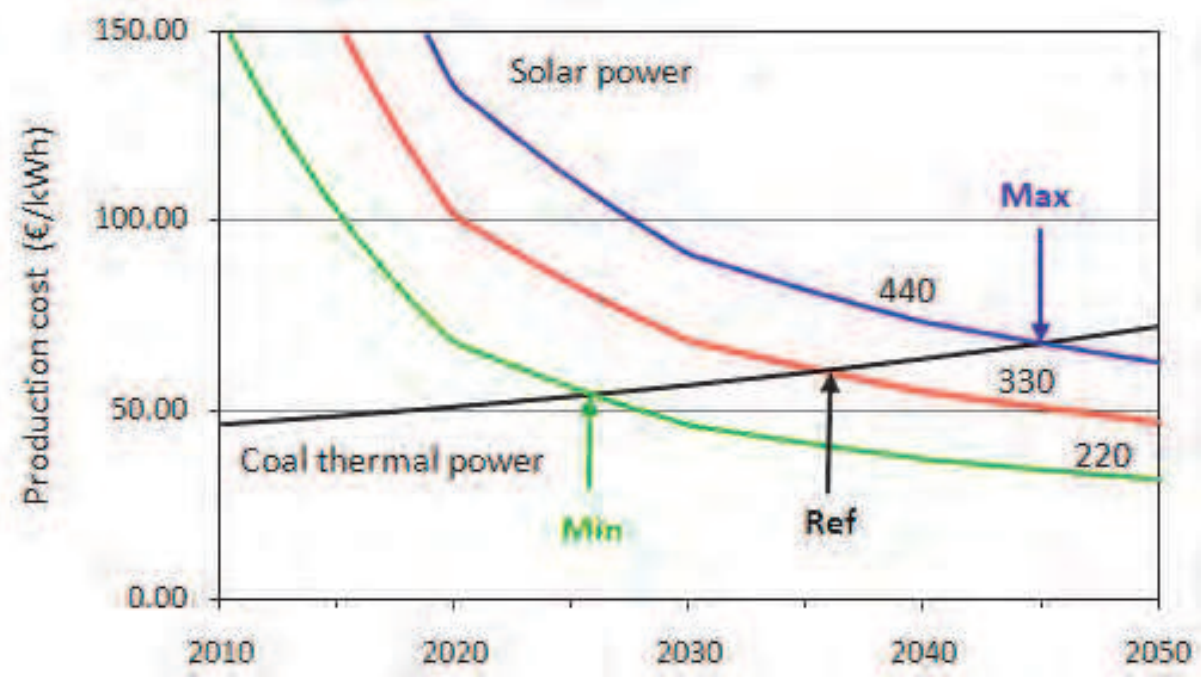

Fig. 5. Estimated electrical energy production costs for the period from 2010 to 2050 by solar photovoltaic and coal thermal power stations. Electricity production costs by solar photovoltaic are shown with estimated current minimum, reference and maximum production costs of 220, 330 and $440 € / M W h$, respectively. (EREC, 2008)

penetration will be out of the scope of the study (later than in 2060). On the other hand, if there would be a $50 \%$ increase in the growth rate, the market penetration would take place already in 2023. This shown clearly that technological development depends strongly on the manufacturing volume, when learning rate is high. Electricity production capacity by solar photovoltaic power has been growing during the last decade with the growth rates presented in Figure 2 and there are no reasons to anticipate that the growth rate would be lower than the forecasted ones (EPIA, 2008; EREC, 2008; IEA, 2010). The growth rate forecasts can be actually considered to be slightly pessimistic and even somewhat higher growth rates can be expected. The strong dependence between technology development and production volume of evolving renewable electricity production technologies with high learning rates is also a clear signal for political decision makers. Market penetration of evolving renewable electricity production technologies can be can facilitates by supporting the market growth.

Uncertainties due to other solar photovoltaic electricity generation related variables are also considerable. The second largest uncertainty is related to the learning rate causing a market penetration range from 2026 to 2055. It is not plausible to anticipate that learning rate would increase meaning that the historical long term progress ratio trend would decrease, for example from 0.80 to 0.75 . Progress ratio of a technology does not usually decrease but increases as a function of time, because technology becomes gradually more mature. On the other hand, technological development has turned out to follow learning rates quite consistently. The used reference progress ration of 0.80 for solar photovoltaic was a slightly conservative choice from the set of published progress ratios and, therefore, there are no reasons to anticipate a larger ratio for the near future. Perhaps the main message in here is that one should select the progress ratio carefully to get plausible results.

The third input parameter related to the development of solar photovoltaic was production cost of electricity. On the contrary to earlier variables, the wide range in production costs 
actually exists on the market and does not originate from uncertainties of predictions. Phenomena related to this variable have been already discussed in connection of Figure 5 .

It is not a surprise that uncertainty or range of variation of most variables affecting the coal thermal electricity generation have minimal effects on market penetration of solar photovoltaic electricity. Plausible changes in investment costs or production and maintenance costs can change the time of market penetration only by a year or two (Figure 6). Also the power plant efficiency can change the time of market penetration by five years in maximum. A more important input variable on forecasting point of view is the capacity factor of coal thermal electricity generation introducing a range of 9 years for market penetration. Future development of the coal prize has the biggest effect and uncertainty of 18 years to the forecasted market penetration. The effects and phenomena related to these input variables have been already discussed in more detail in connection of Figures 3 and 4.

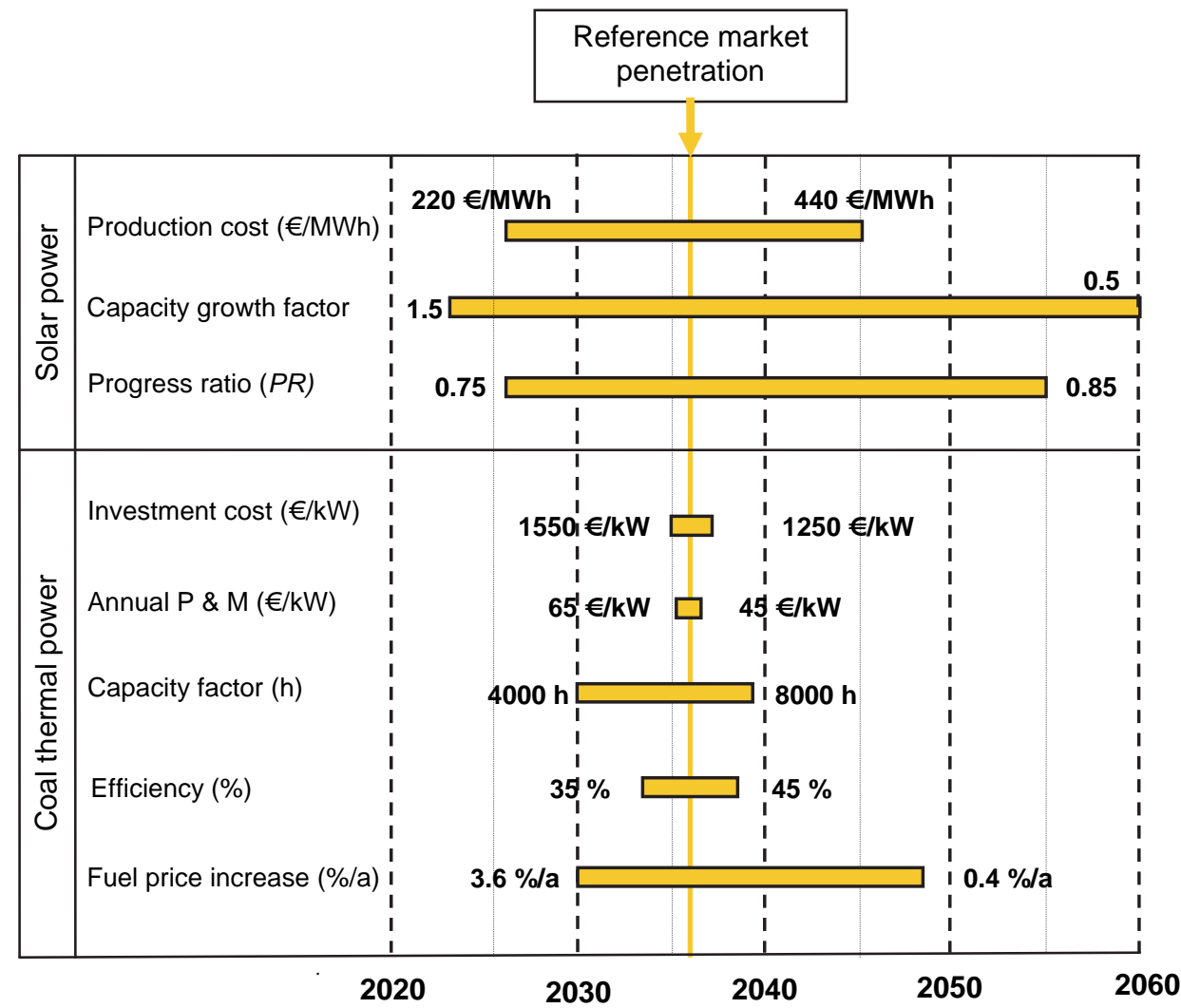

Fig. 6. Time when electrical energy produced by solar photovoltaic power plant has the same production cost than by thermal coal power stations. The reference market penetration time is shown by a solid line. The bars show the uncertainty of the market penetration with respect to the range of variation of each variable (maximum and minimum values in Table 1) when other variables have their reference values. 
There are also other ways to evaluate the sensitivity of market penetration on uncertainties and range of variation of input variables than to compare their effects one by one to the reference case. For example their combined effect could provide interesting information. However, the uncertainties due combined effect of several variables can be deduced quite reliably from the effects of single variables. Furthermore, the combined effects of several variables are not usually much bigger than the largest effects due to single variables, because the variable with the largest effect dominates the combined effect. To demonstrate this, the market penetration of solar photovoltaic electricity generation was calculated using the minimum and maximum input variable values of coal thermal electricity generation, which led to an earlier market penetration than in the reference case. The outcome was that market penetration would take place in 2025, just five years earlier than in the case of having only the capacity factor changed to its minimum value of $4000 \mathrm{~h}$. One must also point out that it is highly unlikely that all variables would have the extreme values at the same time.

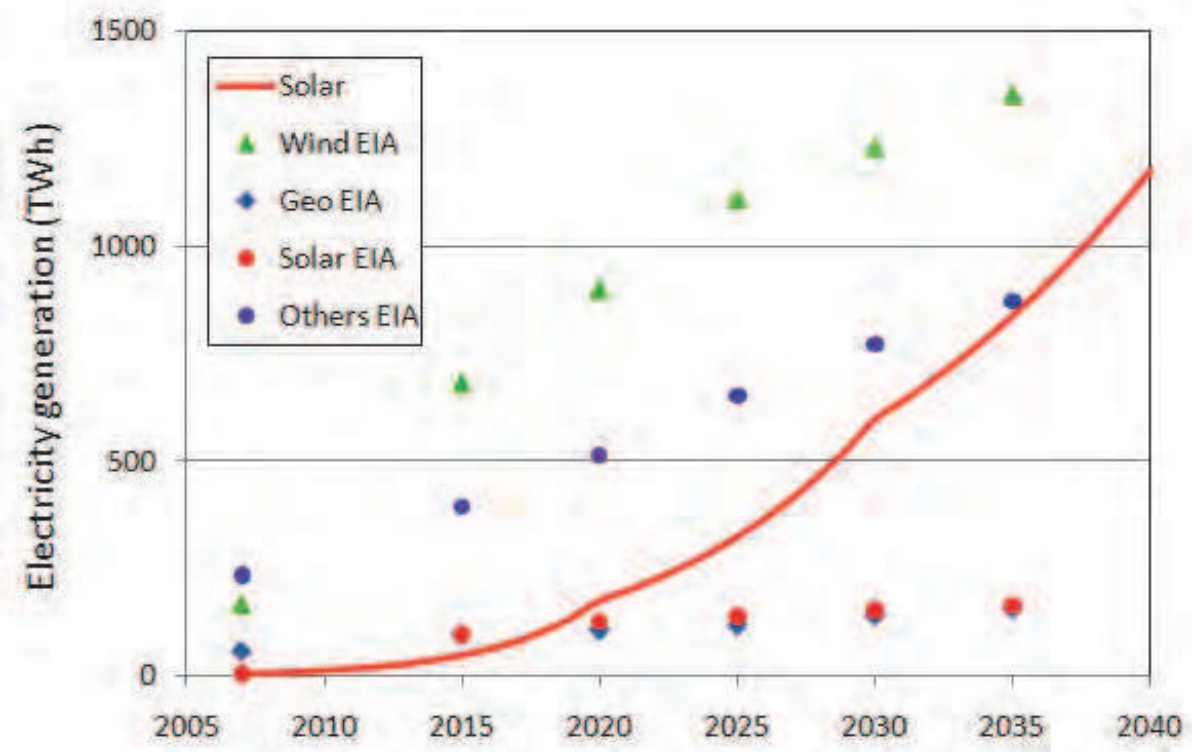

Fig. 7. Annual electricity generation with evolving renewable power production technologies for the period from 2007 to 2035 according to the IEO2010 Reference Case (EIA, 2010b). Values for 2007 are realised historical generation volumes. Others include biomass, waste, tidal, wave and ocean energy. The solid line corresponds to the estimated cumulative solar photovoltaic electricity production according to EREC (Figure 2) using the EIA solar generation in 2007 as a reference value.

Cumulative electricity generation estimates according to the IEO2010 Reference Case (EIA, 2010b) for evolving renewable energy sources for the period from 2005 to 2040 are shown in Figure 7. Also the cumulative solar photovoltaic electricity production corresponding to the estimated capacity growth rate by EREC (Figure 2) is provided using the EIA solar electricity generation in 2007 (EIA, 2010b) as a reference value. The overall renewable energy production growth forecasted by EIA seems to be in balance except for solar power, which is 
in contradiction with other estimates (Figure 2). There are no reasons to believe that solar photovoltaic as a source of electrical energy would stay constant for decades, while it has had the highest capacity growth rate of all forms of producing electrical energy for years. On the other hand the solid line for solar photovoltaic electricity production is consistent with existing information. Around 2020 it will be the second largest renewable source of electrical energy after wind power when hydropower is excluded. Production capacity of wind power will grow fastest during the next few decades, but somewhere around 2050 solar photovoltaic will outpace it being then the largest source of renewable energy in producing electric power.

\section{Conclusion}

The aim of this study was to demonstrate how the market diffusion of new evolving electrical energy production technologies can be forecasted. The dependence of the market diffusion on technology and energy market variables has been analysed. A simple forecasting method has been presented together with uncertainty analyses on the studied variables. The results confirm that it is possible to quantitatively forecast the market penetration of evolving energy technologies. These kinds of analyses can support decision making both on National level and in companies developing energy technology.

The market penetration of solar photovoltaic electricity generation has been studied in detail, because it will be in a major role in generating electrical energy on long term in the future. Coal thermal electricity generation was used as a reference technology for market penetration. The analyses showed that in the reference case solar photovoltaic electricity generation should be competitive without subventions somewhere around 2036. In areas with favourable solar radiation conditions, such as in Los Angeles and Dubai, solar photovoltaic power will achieve grip parity with thermal coal power already in 2026. In less favourable areas, like in Central and North Europe, grid parity will be achieved just around 2045. Also periodicity of the electricity demand affects the market penetration of photovoltaic electricity. If the capacity factor of coal thermal electricity production is only $4000 \mathrm{~h}$ instead of $6000 \mathrm{~h}$ used as a reference value, market penetration will happen in 2030 5 years earlier than in the reference case. If the capacity factor is $8000 \mathrm{~h}$, market penetration will be delayed until 2039. As a summary, the market penetration is strongly a local matter.

Market penetration of solar photovoltaic electricity depends also on the forthcoming production capacity growth and the learning rate of the technology. If the learning rate of the solar photovoltaic technology would improve by $5 \%$ from the current trend so that the progress ration would decrease from 0.80 to 0.75 , market penetration would happen 10 years earlier that in the reference case. However, this kind on increased technology learning does not usually take place. The annual increase of the solar photovoltaic electricity production capacity is huge, around $33 \% / \mathrm{a}$. In principle, the growth rate could still increase by half leading to a market penetration already in 2023. Market penetration depends also on the development in other areas of energy technology. One important parameter turned out to be the coal price. If, for example, the high coal price scenario by EPIA (EPIA, 2010) comes true, market penetration of solar photovoltaic will take place 6 years earlier than in the reference case. As a summary there are many technology related uncertainties having major effects to the market penetration of solar photovoltaic electricity generation. 


\section{References}

Armstrong, S. (2001). Principles of Forecasting : A Handbook for Researchers and Practitioners, Kluwer Academic, ISBN 0-7923-7930-6, Boston, USA

Beneking, C. 2007. Perspective for Industrial Development, Proceeding of Second Photovoltaic Mediterranean Conference, Athens, Greek, April 19-20, 2007

British Petroleum (2004). BP Statistical Review of World Energy 2004

British Petroleum (2006). BP Statistical Review of World Energy 2006

EIA, Energy Information Administration (2002). International Energy Outlook 2002, 13.2.2011, Available from http://www.eia.doe.gov/oiaf/

EIA, Energy Information Administration (2006). Annual Energy Outlook 2006 with projections to 2030, 1.3.2011, Available from http:/ / www.eia.doe.gov/ oiaf/

EIA, Energy Information Administration (2010a). Annual Energy Outlook 2010 with Projections to 2035, 13.2.2011, Available from http:/ / www.eia.doe.gov/oiaf/

EIA, Energy Information Administration (2010b). International Energy Outlook 2010, 13.3.2011, Available from http://www.eia.doe.gov/oiaf/

EPIA, Europian Photovoltaic Industry Association, 2010. Unlocking the Sunbelt Potential of Photovoltaics until 2013, Brussels, Belgium

EPIA, European Photovoltaic Industry Association \& Greenpeace Association (2008). Solar Generation V - 2008, Solar Electricity for over One Million People and Two Million Jobs by 2020, Brussels, Belgium

EREC, European Renewable Energy Council (2004). Renewable Energy Scenario to 2040, 20.4.2011, Brussels, Belgium, Available from : http://www.erec.org/

EREC, European Renewable Energy Council (2008). Renewable Energy Roadmap 20 \% by 2020, Brussels, Belgium

IEA, International Energy Agency (2003). Renewables for Power Generation, Status E Prospects, Paris, France

IEA, International Energy Agency (2005). Projected Costs of Generating Electricity 2005 Update, Paris, OECD/IEA/NEA

IEA, International Energy Agency (2010a). Key World Energy Statistics, 18.4.2011, Available from http://www.iea.org/

IEA, International Energy Agency (2010b). ETSAP, Energy Technology Systems Analysis Programme, Coal-fired Power, IEA ETSAP Technology Brief E01 - April 2010, Available from http://www.iea.org/

Junginger, H. M. (2005). Learning in Renewable Energy Technology Development, Universiteit Utrecht, Facukteit Scheikunde, ISBN 90-393-0486-6, Utrecht, Netherlands

Martino, J. P. (1993). Technological Forecasting for Decision Making, McGraw-Hill, ISBN 0070407770 , New York, USA

Meredith, J. \& Mantel, S. (1995). Technological forecasting, John Wiley \& Sons, Cincinnati, USA

Parente, V., Goldenberg, J. \& Zilles, R. (2002). Comments on Experience Curves for PV Modules, Progress in Photovoltaic, Vol.10, No.8, (2002), pp. 571-574

Poponi, D. (2003). Analysis of Diffusion Paths for Photovoltaic Technology Based on Experience Curves, Solar Energy, Vol.74, (2003), pp. 331-340 
Rogers, E. (2003). Diffusion of Innovations, Free Press, New York, USA

Valkealahti, S. \& Nevalainen T. (2007). Forecasting the Market Penetration of Evolving Electric Power Production technologies, Proceedings of the Third IASTED Asian Conference on Power and Energy Systems - AsiaPES 2007, pp. 294-299, ISBN 978-088986-657-7, Phuket, Thailand, April 2 - 4, 2007 


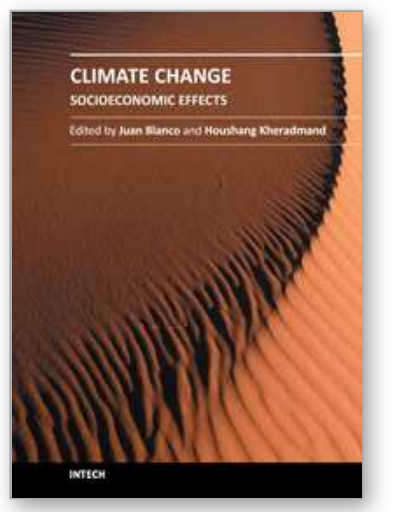

\author{
Climate Change - Socioeconomic Effects \\ Edited by Dr Houshan Kheradmand
}

ISBN 978-953-307-411-5

Hard cover, 454 pages

Publisher InTech

Published online 09, September, 2011

Published in print edition September, 2011

This book shows some of the socio-economic impacts of climate change according to different estimates of the current or estimated global warming. A series of scientific and experimental research projects explore the impacts of climate change and browse the techniques to evaluate the related impacts. These 23 chapters provide a good overview of the different changes impacts that already have been detected in several regions of the world. They are part of an introduction to the researches being done around the globe in connection with this topic. However, climate change is not just an academic issue important only to scientists and environmentalists; it also has direct implications on various ecosystems and technologies.

\title{
How to reference
}

In order to correctly reference this scholarly work, feel free to copy and paste the following:

Seppo Valkealahti (2011). Forecasting the Future of Renewables, Climate Change - Socioeconomic Effects, Dr Houshan Kheradmand (Ed.), ISBN: 978-953-307-411-5, InTech, Available from:

http://www.intechopen.com/books/climate-change-socioeconomic-effects/forecasting-the-future-of-renewables

\section{INTECH}

open science | open minds

\section{InTech Europe}

University Campus STeP Ri

Slavka Krautzeka 83/A

51000 Rijeka, Croatia

Phone: +385 (51) 770447

Fax: +385 (51) 686166

www.intechopen.com

\section{InTech China}

Unit 405, Office Block, Hotel Equatorial Shanghai

No.65, Yan An Road (West), Shanghai, 200040, China

中国上海市延安西路65号上海国际贵都大饭店办公楼 405 单元

Phone: +86-21-62489820

Fax: +86-21-62489821 
(C) 2011 The Author(s). Licensee IntechOpen. This chapter is distributed under the terms of the Creative Commons Attribution-NonCommercialShareAlike-3.0 License, which permits use, distribution and reproduction for non-commercial purposes, provided the original is properly cited and derivative works building on this content are distributed under the same license. 